\title{
Air Travel for Subjects Receiving Long-Term Oxygen Therapy
}

\author{
Christina D Campbell MD, Matthew W Smyth MD, Lindsay Brown RN, and Emer Kelly MD
}

\begin{abstract}
BACKGROUND: Ambulatory oxygen $\left(\mathrm{O}_{2}\right)$ is the recommended treatment for hypoxemia at rest or induced by exercise. Commercial aircraft often fly at altitudes of 30,000 feet; their cabins are pressurized to altitudes of 6,000-8,000 feet, with an equivalent $\mathrm{F}_{\mathrm{IO}_{2}}$ of $0.15 . \mathrm{O}_{2}$ supplementation, for those receiving baseline ambulatory $\mathrm{O}_{2}$, is paramount. METHODS: We gathered information on subjects' experience traveling with supplementary oxygen and reasons individuals receiving $\mathrm{O}_{2}$ do not travel. Subjects were identified using a home oxygen database. Data were gathered by postal questionnaire. The objective of this study was to gather information relevant to subjects' experience organizing travel with supplementary oxygen and their experience of traveling itself. RESULTS: Between 2013 and 2015, 512 patients were entered into the database: 277 were excluded ( 269 had died, 8 had incomplete records). We sent 235 questionnaires, and 50 responses were received (21\% response rate). Of these, $11(22 \%)$ were returned as the patient had died, $20(40 \%)$ had not traveled by air, $11(22 \%)$ had flown with $\mathrm{O}_{2}, 4(8 \%)$ no longer used $\mathrm{O}_{2}$, and $4(8 \%)$ forms were incomplete. Of those who traveled with $\mathrm{O}_{2}, 54 \%$ found it complicated to organize their trip, $72 \%$ found it complicated to access information, and $81 \%$ would fly again. Regarding those who had never flown with $\mathrm{O}_{2}, 35 \%$ were unaware that $\mathrm{O}_{2}$ was available on commercial aircraft, $30 \%$ had no wish to travel, and $30 \%$ had worries regarding their health. CONCLUSIONS: Air travel is challenging; however, those who did travel reported a mainly positive experience. Increasing available information on options for travel should help individuals. Key words: air travel; oxygen; COPD. [Respir Care 2018;63(3):326-331. (C) 2018 Daedalus Enterprises]
\end{abstract}

\section{Introduction}

The numbers of individuals traveling by plane are increasing, with an estimated 3.4 billion flying in 2015, and this is expected to rise to 7.4 billion/y by 2034 , as quoted by the International Air Transport Association (http://www. iata.org/pressroom/pr/Pages/2015-11-26-01.aspx, Accessed January 21, 2017). With an aging population and esti-

\footnotetext{
The authors are affiliated with the Respiratory Department, St Vincent's University Hospital, Dublin, Ireland.

Dr Campbell presented a version of this work in poster format at the European Respiratory Society International Congress, held September 6, 2016, in London, United Kingdom, and the Irish Thoracic Society Scientific Meeting, held November 18, 2016, in Dublin, Ireland.
}

Correspondence: Christina D Campbell MD, Respiratory Department, St Vincent's University Hospital, Elm Park, Dublin 4, Ireland. E-mail: christinadcampbell@gmail.com.

DOI: $10.4187 /$ respcare. 05522 mated 384 million people living with COPD worldwide, ${ }^{1}$ a significant proportion of the traveling population will have underlying lung disease. Ambulatory oxygen $\left(\mathrm{O}_{2}\right)$ is a well-established treatment for hypoxemia at rest or induced by exercise, and use of in-flight oxygen is increasing by $10-12 \% / y .{ }^{2}$ Commercial aircraft often fly at altitudes of 30,000 feet; their cabins are pressurized to altitudes of 6,000-8,000 feet, with an equivalent $\mathrm{F}_{\mathrm{IO}_{2}}$ of $0.15 .{ }^{3} \mathrm{O}_{2}$ supplementation, for those receiving baseline ambulatory $\mathrm{O}_{2}$, is paramount. On a practical level, traveling with ambulatory oxygen provides many physical and financial obstacles for patients; mobility difficulties have been shown to be associated with COPD ${ }^{4}$ and pulmonary fibrosis. ${ }^{5}$

Many studies have investigated the role of pre-assessment of patients with lung disease, not requiring ambulatory oxygen at baseline, before air travel. ${ }^{6}$ It is well established that individuals requiring supplemental oxygen therapy will require supplemental oxygen when flying; however, to date, no studies have examined the individuals' attitudes to and perceptions of air travel. 
The objective of this study was to gather information relevant to subjects' experience organizing travel with supplementary oxygen and their experience of traveling itself. For this purpose, patients in a supplementary oxygen database were invited to answer a questionnaire regarding their experience of air travel to include limitations, obstacles to air travel, personal experiences, and reasons why they would not travel.

\section{Methods}

\section{Subjects}

This observational, cross-sectional study was carried out in St Vincent's University Hospital in Dublin, Ireland. Subjects were identified using the hospital database of users of long-term oxygen therapy. Subjects had previously undergone a long-term oxygen assessment, and hypoxemia at baseline was established. Excluded were patients were who were using ambulatory oxygen for palliation, patients who had died, and any patients with incomplete records. Five hundred twelve patients were identified, with 277 excluded and 235 invited to participate.

\section{Questionnaire}

Data were gathered using an air-travel questionnaire, which was designed for the study and tested on age-matched controls. Information related to the organization of ambulatory oxygen during travel, previous knowledge of flying with long-term oxygen, availability and source of information, interactions with the airport and airline staff, the experience of flying with oxygen, any barriers to travel, and inflight respiratory symptoms was collected. Quantitative and qualitative data were gathered; open- and closed-ended questions were used, with a rating scale (from very good to poor) and "tick all that apply" styles used, with additional space for free text and comments. The questionnaires were delivered by mail, with a prestamped envelope for return.

\section{Ethics}

St Vincent's University Hospital Ethics Board granted ethics approval. An information and consent form was included with the postal questionnaire. Contact information for any further queries was included.

\section{Statistical Analysis}

We used descriptive statistics for analysis of variables (means and proportions) for each cohort. Analysis was carried out using SPSS (Version 20 SPSS, Chicago, Illinois). For qualitative information, free text feedback was categorized into groups.

\section{QUICK LOOK}

Current knowledge

Ambulatory oxygen is the recommended treatment for hypoxemia induced by exercise or at rest. When traveling by plane, commercial aircraft cabins are pressurized to altitudes of $6,000-8,000$ feet with an equalization $\mathrm{F}_{\mathrm{IO}_{2}}$ of 0.15 . Oxygen supplementation for those requiring long-term oxygen is crucial.

\section{What this paper contributes to our knowledge}

Individuals requiring long-term oxygen therapy face many barriers to air travel, related to information availability, logistical pressures, and health concerns. Many subjects who required ambulatory oxygen were unaware that plane travel was an option for them; however, when traveling, the majority of subjects who did travel reported a positive experience.

\section{Results}

\section{Response}

Five hundred twelve patients were initially identified on the database, 235 once exclusion criteria were applied (Fig. 1). Of the 235 questionnaires sent, we received 50 responses ( $21 \%$ response rate); of those 50 subjects, 11 had flown with oxygen (22\%), 20 had not (40\%), 11 subjects died (22\%), 4 sent blank replies (8\%), and 4 were no longer using ambulatory oxygen (8\%).

\section{Demographics}

The average age of the subjects who had flown with long-term oxygen was $70 \mathrm{y}$; in the group who had not, it was $68 \mathrm{y}$. The predominant diagnoses across the groups were COPD (9 subjects [82\%] of those who had traveled, 9 subjects [45\%] of those who had not) and interstitial lung disease (1 subject [9\%] of those who had flown, 6 subjects [30\%] of those who had not), and other diagnoses included chronic respiratory failure secondary to kyphoscoliosis, post-cardiac arrest, and lung cancer (Table 1).

\section{Flight Experience, Quantitative Data}

Of those who had flown with ambulatory oxygen, 6 (54\%) found it complicated or very complicated to organize travel (Fig. 2A). To access the required information, $8(73 \%)$ found it complicated or very complicated (Fig. 2B). The majority of the information was accessed from non-medical sources, 3 (27\%) phoning the airline com- 


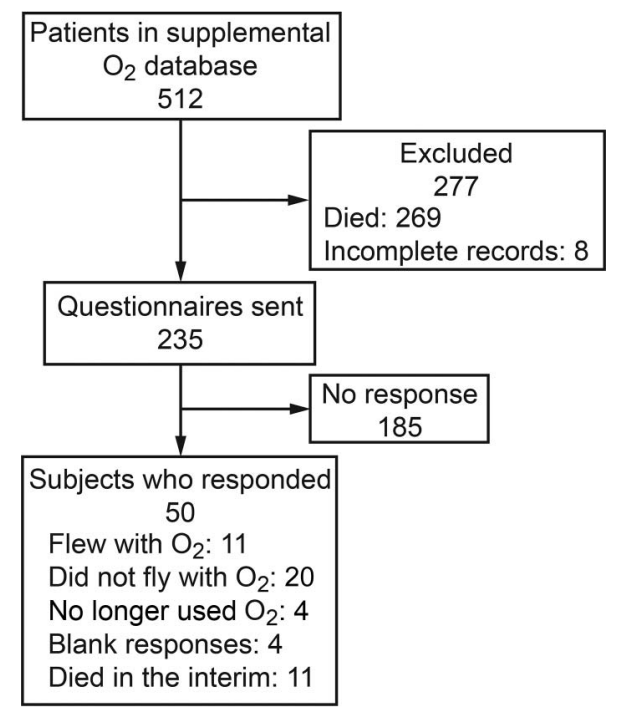

Fig. 1. Flow chart.

Table 1. Demographics of Respondents

\begin{tabular}{lcc}
\hline \hline \multicolumn{1}{c}{ Characteristics } & $\begin{array}{c}\text { Had Flown With } \\
\text { Supplementary Oxygen } \\
(n=11)\end{array}$ & $\begin{array}{c}\text { Had Not } \\
\text { Flown } \\
(n=20)\end{array}$ \\
\hline Age, average (range) y & $70(60-86)$ & $68(47-89)$ \\
Diagnosis, $n(\%)$ & $9(82)$ & $9(45)$ \\
COPD & $1(9)$ & $6(30)$ \\
ILD & $1(9)$ & $5(25)$ \\
Other* & 2 & 1.5 \\
Time receiving LTOT, average y & & \\
*Chronic respiratory failure secondary to kyphoscoliosis, post-cardiac arrest, and lung cancer. \\
ILD = interstitial lung disease \\
LTOT = long-term oxygen therapy
\end{tabular}

pany and $3(45 \%)$ accessing the airline website, with only $2(18 \%)$ using their physician or hospital doctor. Eight subjects $(72 \%)$ canvassed multiple airline providers, all using 2 or 3 different providers.

During the journey, the majority of subjects felt the airlines were very competent or somewhat competent at dealing with ambulatory oxygen (63\%) compared with not at all (27\%). Six subjects (54\%) felt well supported by airport staff (Fig. 2C).

During the flight, 6 subjects felt unwell. Symptoms they described were shortness of breath at rest (3 subjects [50\%]), shortness of breath on exertion ( 6 subjects [100\%]), wheeze (4 subjects [66\%]), and cough (2 subjects [33\%]) (Fig. 3). Some subjects reported multiple symptoms, expressed in Figure 3.

Regarding the individuals who had never flown with ambulatory oxygen, the most common reason stated was that they were unaware oxygen was available on commercial airplanes (7 [20\%]). Six subjects had no wish to travel by plane (17\%). This was closely followed by worries regarding health: "worried about my breathing problems" (4 subjects [20\%]) and "worries about other health problems" (2 subjects [10\%]). Many subjects reported more than one reason for not traveling by airplane; reasons expressed as percentage of total responses given displayed in Figure 2.

The vast majority of individuals who have flown would fly again (9 subjects [81\%]). Those who would not fly again (2 subjects [18\%]) felt that it was too much work to organize, and 2 subjects (18\%) felt too unwell on the flight.

When asked how these barriers could be overcome, the most common need identified by those subjects who had not traveled by airplane $(n=20)$ was written information from a respiratory physician or nurse (10 subjects [50\%]), followed by written information from the airline (6 subjects $[30 \%])$.

Of those subjects who had never flown with ambulatory oxygen (20 subjects), 7 subjects were unaware that ambulatory oxygen was available on commercial air travel or that airlines would provide supplementary oxygen, 6 had no wish to fly, 4 subjects were worried about their breathing on a plane, 2 had concerns about other medical conditions, 4 had limited mobility, and 1 found it too difficult to organize. No subject cited cost as a reason for not traveling on a plane. Three subjects chose multiple reasons for not traveling by plane (Fig. 4).

\section{Qualitative Feedback}

The majority of subjects had a positive travel experience, with statements such as "People in the airport could not be more helpful," "Very enjoyable," "I have no problem flying and wish I could do more of it," and "I was well looked after from the staff. One telephone call it took me, and I was very happy" (Table 2).

Some subjects did encounter difficulties, such as "I flew to Glasgow and the oxygen cylinder did not work. I was at the point of being disembarked when the captain then decided to use the emergency oxygen. I managed to delay the flight taking off 15-20 min," and "Had to use overhead oxygen on the flight as the batteries for portable oxygen ran out, cylinders not allowed." Other subjects found it difficult to coordinate their ambulatory oxygen, stating, "It was very arduous having to bring my own portable oxygen and luggage; this should be free and on board every flight so that travelers needing oxygen can travel easier." Finally, some subjects felt increased symptoms during the flight, leading to a negative experience: "Terrible, never again! I felt very ill" (Table 2). 

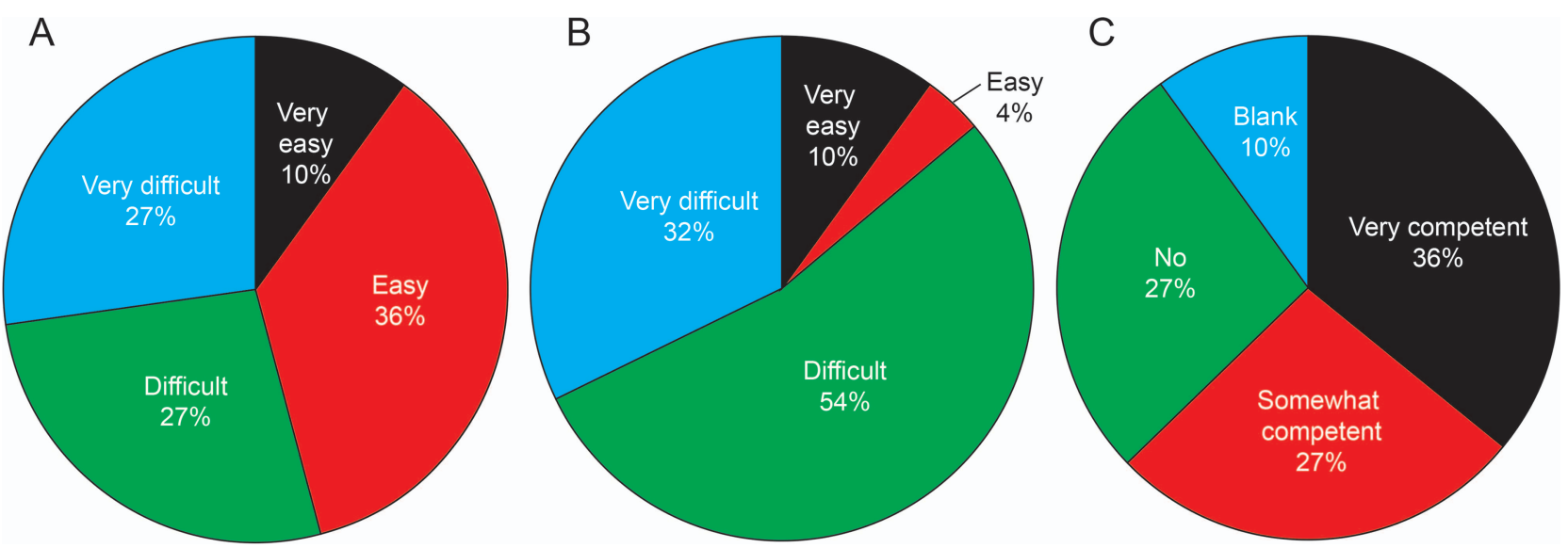

Fig. 2. Experiences of subjects who flew with supplemental oxygen. A: Was traveling with $\mathrm{O}_{2}$ easy to organize? B: Was information regarding air travel with supplemental $\mathrm{O}_{2}$ easy to find? C: Was the airline able to manage your supplemental $\mathrm{O}_{2}$ ?

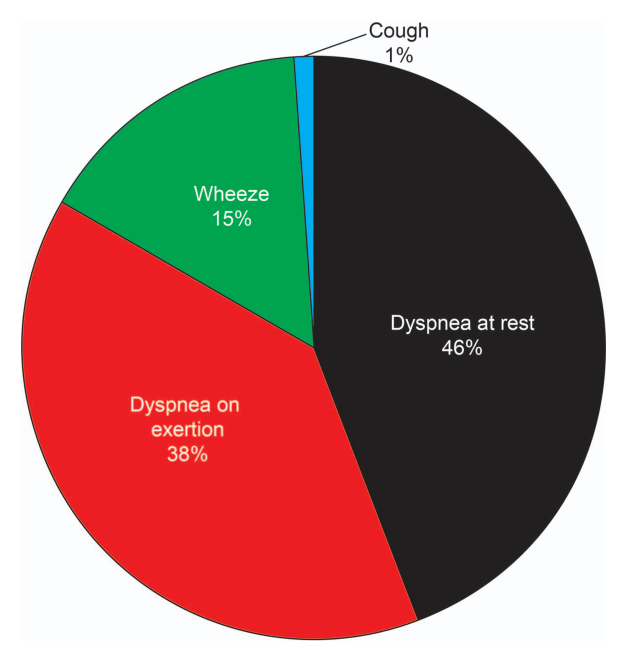

Fig. 3. Symptoms of subjects flying with supplemental oxygen who felt unwell during the flight.

\section{Discussion}

Our investigation of patient experience flying with ambulatory oxygen shows that a minority of users of ambulatory oxygen travel by plane. Of the individuals surveyed, only $22 \%$ had traveled by air. This is clearly a low rate and could not be used as a reliable frequency of air travel rates by patients with severe pulmonary disease; however, it does indicate that some proportion of these patients do travel by plane and should be accommodated. Health concerns are the major barrier to travel, followed by limited mobility. The major difficultly faced by those who did fly with ambulatory oxygen was organizing oxygen provision during travel, followed by accessing information. The majority of information accessed was from the airline company, predominantly online, with one individual organizing oxygen by telephone.

The population investigated in this study reflects the patient cohort that is prescribed long-term oxygen therapy and

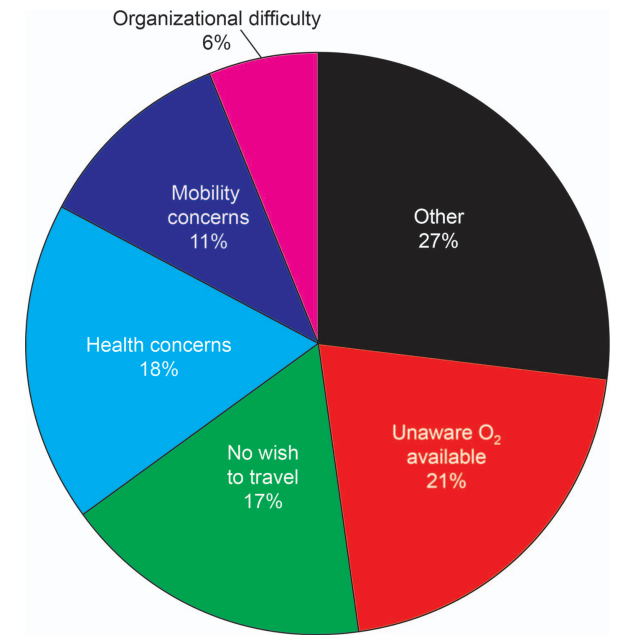

Fig. 4. Reasons given by subjects on supplemental oxygen who did not fly.

confirms that this population represents individuals with multiple comorbidities and a high mortality rate. Although we do not have specific data for this patient cohort, co-morbidities such as cardiac disease, hypertension, diabetes mellitus, osteoporosis, obstructive sleep apnea, metabolic syndrome, and psychological disorders are reported in COPD. ${ }^{7,8}$ Previous studies reflect the high morbidity and mortality in this cohort of subjects, with a median survival of $<2 y$ after oxygen therapy is started. ${ }^{9}$ We know that most patients starting longterm oxygen therapy for therapeutic indications are elderly women with multiple comorbidities. ${ }^{10-14}$. Our response rate for this study was $21 \%$, which is low. Response rates to postal surveys have been falling since the 1970s. ${ }^{15}$ Similar questionnaire-based studies eliciting respiratory symptoms have shown low response rates: $33 \%$ in a Swedish study ${ }^{15}$ and $36 \%$ in a study of subjects with refractory breathlessness. ${ }^{16}$ The latter study would have a similar patient population in terms of disease severity. The high morbidity and 
Table 2. Qualitative Feedback: Negative and Positive

\begin{tabular}{|c|c|}
\hline Negative Feedback & Positive Feedback \\
\hline $\begin{array}{l}\text { I flew to Glasgow and the oxygen cylinder did not work. I was at } \\
\text { the point of being disembarked when the captain then decided } \\
\text { to use the emergency oxygen. I managed to delay the flight } \\
\text { taking off } 15-20 \text { min. } \\
\text { It was very arduous having to bring my own portable oxygen and } \\
\text { luggage; this should be free and on board every flight so that } \\
\text { travelers needing oxygen can travel easier. } \\
\text { Had to use overhead oxygen on the flight as the batteries for } \\
\text { portable oxygen ran out, cylinders not allowed. } \\
\text { Terrible, never again! I felt very ill. } \\
\text { Experience was very bad; staff were very unhelpful and made me } \\
\text { feel like I was being an uncooperative passenger despite having } \\
\text { paid extra for them to provide assistance. } \\
\text { Airport not very knowledgeable of customers that required } \\
\text { oxygen. Didn't seem to be happy with me taking it on in the } \\
\text { first place; seen as a problem. } \\
\text { The worst part was getting my consultant doctor to write the } \\
\text { proper description of the oxygen the airline wanted me to take. }\end{array}$ & $\begin{array}{l}\text { People in the airport could not be more helpful. } \\
\text { Every time I used to fly, in a week I would end up in hospital. I love } \\
\text { flying; I nearly had to stop because I was so unwell after my trips. } \\
\text { I looked at the problems and sorted it. It took awhile to find the } \\
\text { right mask; now it is great. Happy days again. } \\
\text { Very enjoyable. } \\
\text { I have no problem flying and wish I could do more of it. } \\
\text { I was well looked after from the staff. One phone call it took me, and } \\
\text { I was very happy. } \\
\text { Bit of work involved in getting access to relevant person in airline to } \\
\text { organize paperwork; cannot download from website. They then } \\
\text { e-mail the forms for printing and completing. Cabin crew very } \\
\text { helpful, even moving a passenger so that my wife and I had the } \\
\text { use of } 3 \text { seats, one for the machine. }\end{array}$ \\
\hline
\end{tabular}

mortality rate of this population is likely to have been a contributing factor in this response rate. Some subjects who had died were mailed questionnaires, and this was an understandable source of distress to families. Although the database is regularly updated, the high mortality rate meant that the questionnaire was mailed during the short interval before database update. It was for this reason that the planned repeat delivery of the questionnaire was cancelled.

In treating individuals in a holistic manor, travel may be of great importance to quality of life. For many individuals, their physician may be their first port of call and should be able to provide information. In our study, $50 \%$ of individuals surveyed expressed the need for information from respiratory physicians or respiratory nurse specialists, ranking higher than information from an airline (30\%). There are many resources available at local and international levels to guide patients and their caring physicians with regard to traveling with oxygen. ${ }^{3,17,18}$ Interestingly, only $5 \%$ of subjects who had never flown with ambulatory oxygen felt that organization was a barrier to travel, showing that this may be a hidden barrier that only presents when organizing travel plans.

While traveling, it is encouraging to note that individuals did not feel that their ambulatory oxygen was a burden, and the majority of travelers $(64 \%)$ felt that the airlines were able to manage their oxygen requirements and felt well supported by the staff. One recipient stated, "I have no problems flying and only wish I could have more of it," and another individual found it "very enjoyable."

While on the flight, some subjects did feel unwell, 55\%, as would be expected, given that this cohort are at the severe end of the spectrum of respiratory disease. Symptoms expressed included shortness of breath and wheeze. However, it is encouraging to note that despite the appar- ent predominance of respiratory symptoms, only a third of these subjects felt that they were too unwell to attempt another plane journey. The increased incidence of symptoms during flying is consistent with previous studies. ${ }^{19,20}$ Respiratory symptoms of dyspnea and air hunger during air travel were reported by $21 \%$ of subjects with COPD, compared with $4 \%$ of healthy subjects, but these were not subjects with oxygen supplementation.

Regarding the health concerns expressed by subjects who had never attempted to travel, $20 \%$ of subjects cited this as a reason to avoid travel, and $10 \%$ had concerns regarding other health problems. However, this did not appear to be a major concern of those who had traveled. Eighty-one percent of those who flew would fly again, and of those who would not, only $18 \%$ felt that their health would prevent them from flying again. Physicians and health-care providers can inform potential travelers regarding their options and reassure them that the majority of patients travel with minimal difficulties.

Concerning the subjects who had never flown with ambulatory oxygen, again information availability was the biggest barrier; $35 \%$ of recipients were unaware that ambulatory oxygen was available during plane travel. To our knowledge, this is the first study to establish this lack of patient knowledge in relation to their travel options. When assessing healthrelated quality of life, the World Health Organization HealthRelated Quality of Life Scale examines difficulties with transport and access to transport. ${ }^{21}$ Patient education in COPD has been shown to improve patient outcomes, ${ }^{22}$ and this should be expanded to include travel options. This is reflected in the qualitative feedback, with one subject stating, "Many thanks for giving me something to look forward to!" Conversely, $30 \%$ of subjects had no wish to fly; reasons given were not having a passport or never having flown previously. Interest- 
ingly, no subject felt that cost was a barrier, although this has been previously stated in the literature, ${ }^{3,23}$ suggesting that the benefits of travel outweigh the costs involved.

Limitations for this study include the relatively small sample size, in a single center. The prospective design of the questionnaire, asking subjects about their experience, may lead to over- or underreporting of negative or positive experiences. Postal questionnaire surveys traditionally have a low return rate. ${ }^{24}$ Second, in this patient population, other factors, independent of their oxygen dependence, will affect their ability to travel, including mobility, ${ }^{4,5}$ other medical co-morbidities, ${ }^{10-14}$ and a simple lack of interest in traveling. Further studies are required to ascertain the influence of these other barriers to travel.

\section{Conclusions}

This study has shown that, for subjects requiring supplementary oxygen therapy, travel by airplane was a generally positive experience. This is particularly relevant with an increasing patient population with chronic lung disease ${ }^{1}$ combined with a growing traveling population ${ }^{25}$ and increasing use of long-term oxygen therapy. ${ }^{2}$ The main barriers to travel found were lack of patient education, lack of information available, and difficulty accessing information. Patient and health-care worker education is paramount to improve patient quality of life. More studies are required to further examine patient experience and barriers to travel and how to address these barriers to improve individual experience for our subjects.

\section{REFERENCES}

1. Adeloye D, Chua S, Lee C, Basquill C, Papana A, Theodoratou E, et al. Global and regional estimates of COPD prevalence: systematic review and meta-analysis. J Glob Health 2015;5(2):020415.

2. Gendreau MA, DeJohn C. Responding to medical events during commercial airline flights. N Engl J Med 2002;346(14):1067-1073.

3. Ahmedzai S, Balfour-Lynn IM, Bewick T, Buchdahl R, Coker RK, Cummin AR, et al. Managing passengers with stable respiratory disease planning air travel: British Thoracic Society recommendations. Thorax 2011;66(Suppl 1):i1-i30.

4. Schnell K, Weiss CO, Lee T, Krishnan JA, Leff B, Wolff JL, Boyd C. The prevalence of clinically-relevant comorbid conditions in patients with physician-diagnosed COPD: a cross-sectional study using data from NHANES 1999-2008. BMC Pulm Med 2012;12:26.

5. De Vries J, Seebregts A, Drent M. Assessing health status and quality of life in idiopathic pulmonary fibrosis: which measure should be used? Respir Med 2000;94(3):273-278.

6. Edvardsen A, Akerø A, Christensen CC, Ryg M, Skjønsberg OH. Air travel and chronic obstructive pulmonary disease: a new algorithm for pre-flight evaluation. Thorax 2012;67(11):964-969.
7. Chatila WM, Thomashow BM, Minai OA, Criner GJ, Make BJ. Comorbidities in chronic obstructive pulmonary disease. Proc Am Thorac Soc 2008;5(4):549-555.

8. Hillas G, Perlikos F, Tsiligianni I, Tzanakis N. Managing comorbidities in COPD. Int J Chron Obstruct Pulmon Dis 2015;10:95-109.

9. Ahmadi Z, Sundh J, Bornefalk-Hermansson A, Ekström M. Longterm oxygen therapy 24 vs $15 \mathrm{~h} /$ day and mortality in chronic obstructive pulmonary disease. PLoS One 2016;11(9):e0163293.

10. Franklin KA, Gustafson T, Ranstam J, Ström K. Survival and future need of long-term oxygen therapy for chronic obstructive pulmonary disease-gender differences. Respir Med 2007;101(7):1506-1511.

11. Cranston JM, Crockett AJ, Moss JR, Alpers JH. Domiciliary oxygen for chronic obstructive pulmonary disease. Cochrane Database Syst Rev 2005;(4):CD001744.

12. Crockett AJ, Cranston JM, Moss JR, Alpers JH. Survival on long-term oxygen therapy in chronic airflow limitation: from evidence to outcomes in the routine clinical setting. Int Med J 2001;31(8):448-454.

13. Ekström MP, Wagner P, Ström KE. Trends in cause-specific mortality in oxygen-dependent chronic obstructive pulmonary disease. Am J Respir Crit Care Med 2011;183(8):1032-1036.

14. Ekström MP, Hermansson AB, Ström KE. Effects of cardiovascular drugs on mortality in severe chronic obstructive pulmonary disease. Am J Respir Crit Care Med 2013;187(7):715-720.

15. Rönmark EP, Ekerljung L, Lötvall J, Torén K, Rönmark E, Lundbäck B. Large scale questionnaire survey on respiratory health in Sweden: effects of late- and non-response. Respir Med 2009;103(12): $1807-1815$.

16. Reilly CC, Bausewein C, Pannell C, Moxham J, Jolley CJ, Higginson IJ. Patients' experiences of a new integrated breathlessness support service for patients with refractory breathlessness: results of a postal survey. Palliat Med 2016;30(3):313-322.

17. Long D, Deering B, Costello R. Travelling with oxygen. COPD Support Ireland 2017. January 13, 2017. http://copd.ie/living-withcopd/holidays-and-travel/travelling-with-oxygen/. Accessed November 12, 2017.

18. ATS/ERS Task Force. Standards for the diagnosis and treatment of patients with COPD: section for patients. European Respiratory Society 2004. http://www.ers-education.org/guidelines.aspx.

19. Edvardsen A, Ryg M, Akerø A, Christensen CC, Skjønsberg OH. COPD and air travel: does hypoxia-altitude simulation testing predict in-flight respiratory symptoms? Eur Respir J 2013;42(5):1216-1223.

20. Edvardsen A, Akero A, Hardie JA, Ryg M, Eagan TM, Skjønsberg $\mathrm{OH}$, Bakke PS. High prevalence of respiratory symptoms during air travel in patients with COPD. Respir Med 2011;105(1):50-56.

21. World Health Organization. Measuring quality of life. http://www. who.int/healthinfo/survey/whoqol-qualityoflife/en/. Accessed November 12, 2017.

22. Gallefoss F. The effects of patient education in COPD in a 1-year follow-up randomised, controlled trial. Patient Educ Couns 2004; 52(3):259-266.

23. Walker J, Kelly PT, Beckert L. Airline policy for passengers requiring supplemental in-flight oxygen. Respirology 2009;14(4):589-594.

24. Cook JV, Dickinson HO, Eccles MP. Response rates in postal surveys of healthcare professionals between 1996 and 2005: an observational study. BMC Health Serv Res 2009;9:160.

25. International Air Transport Association . IATA air passenger forecast shows dip in long-term demand. November 26, 2015. http://www. iata.org/pressroom/pr/Pages/2015-11-26-01.aspx. Accessed November 12, 2017. 